\title{
AC 2012-3007: UPRM CHEM E SUSTAINABLE ENERGY DEMOS, WORK- SHOPS, TOWN HALL MEETINGS, ETC.: WORKING THE PIPELINE
}

\author{
Dr. Jos Colucci Ros P.E., University of Puerto Rico, Mayagez
}

Jos A. Colucci Ros is a professor of chemical engineering at the University of Puerto Rico, Mayagez (UPRM). He has received teaching and research awards, and professional service recognition such as Chemical Engineer of the Year in Puerto Rico, Distinguished CHEM E Professor (UPRM-CHEME) and Researcher (UPR), and 2009 EPA Environmental Quality Award. He has industry and management experience, and has held leadership positions at UPRM such as Head of the Chemical Engineering Department, Associate Dean of Research in Engineering and UPRM R\&D Center Director. His pioneering work in the areas of biodiesel, fuel cells and other renewable strategies and technologies is widely recognized in Puerto Rico. His annual research funding is approximately $\$ 175,000$ mostly from Federal Agencies (DOE, DHS) and Sloan Foundation.

\section{Prof. Efrain O’Neill-Carrillo, University of Puerto Rico, Mayagez}

Efran O'Neill-Carrillo is a professor of power engineering at the University of Puerto Rico, Mayagez (UPRM). He holds a Ph.D. (Arizona State), an M.S.E.E. (Purdue), and a B.S.E.E. (UPRM). His professional interests include energy policy, sustainable energy, distributed generation, power quality, social and ethical implications of engineering, and technology. He has authored or co-authored more than 60 peer-reviewed journal and conference papers. O'Neill-Carrillo was the founding Director (2007-2010) of the Institute for Tropical Energy, Environment, and Society, leading a group of 15 professors from 10 disciplines in establishing links between energy research and society and influencing energy policy in Puerto Rico (http://iteas.uprm.edu/). O'Neill-Carrillo was also the Education Coordinator at UPRM for the NSF's Center for Power Electronics Systems (CPES) from 2000-2008. He is Associate Director, CIVIS: Center for Resources in General Education, assisting in the administration of the Center, as well as developing student learning modules (sustainability, ethics), a sustainable energy initiative and coordinating the interaction and work of professors from various disciplines in UPRM. He has been energy Advisor for city governments and state agencies in Puerto Rico. He is one of the authors of the study "Achievable Renewable Energy Targets for Puerto Rico's Renewable Portfolio Standard," presenting the potential of renewable energy in Puerto Rico (http://www.uprm.edu/aret). He is also very active in the energy policy debate in Puerto Rico, authoring "Una Nueva AEE," a Spanish document that traces the history of the Puerto Rico Electric Power Authority, presenting potential reforms to the Island's electric system (http://iteas.uprm.edu/recursos.php). O'Neill-Carrillo is a founding member of the Puerto Rico Electric Energy Round Table, a multi-sector group that works on technical and policy alternatives for the future of Puerto Rico's electric system, acting as the Group Coordinator from 2008 to 2010. He is a Senior Member of IEEE, an ABET Program Evaluator and a registered Professional Engineer. His views and work on integrative research and education activities, and his professional service have earned O'Neill-Carrillo UPRM's Outstanding ECE Professor of the Year Award (twice), the Distinguished Electrical Engineer of the Year Award from the CIAPR in May 2004, an Early Promotion to Full Professor from UPRM in Nov. 2004, and the IEEE/PES Walter Fee Outstanding Young Engineer Award in June 2005.

Prof. Miriam del Rosario Fontalvo 


\title{
CHEM E Sustainable Energy Demos, Workshops, Town Hall Meetings and Other Stakeholder Engagement: Working the Pipeline José A. Colucci-Ríos, Miriam Fontalvo, Efraín O’Neill-Carrillo University of Puerto Rico-Mayagüez
}

\begin{abstract}
A Sustainable Energy Laboratory in the Chemical Engineering Department has been instrumental in the effective incorporation of sustainability into chemical education targeting audiences (hundreds per year) from the whole spectrum: K-12, undergraduate students, graduate students and the general public. The latter includes strong alliances with various stakeholders that led to several awards such as the 2009 EPA Region II Environmental Quality Award. The laboratory's cultural transformation started in 1995 sponsored by the Department of Energy with environmentally friendly topics related to renewable energy such as Fuel Cell applications, Solar Detoxification, Biomass Conversion processes, etc. Workshops and Demonstrations were integral components of those efforts. At the turn of the century the focus increased to include sustainability principles such as social equity, ethics and community participation but with energy as the central theme. This focus has been primarily supported by a Sustainable Energy Initiative implemented in the College of Engineering. These activities are effective in providing information to various stakeholders and increasing interest in sustainable energy.
\end{abstract}

\section{Sustainability}

The world's complex problems require a holistic approach that integrates the expertise and will of many diverse fields and individuals. Sustainability presents a holistic approach to integrate not only the technological dimension, usually tied up with economic considerations, but also the environmental as well as the social dimensions of development. The concept of sustainability evolved from ideas on human impact on the environment and the welfare of people. One of the first international forums on the subject was the Stockholm Conference on Human Environment in 1972 [1]. There are many definitions of sustainability or sustainable development. In fact, there is literature comparing the various stances on sustainability, classifying definitions in terms of weak, strong or normative sustainability (for an example comparing Solow, Holling, Leopold, Pearce and Barbier see Chapter 8 of Norton's Sustainability [2]). There are also various indicators of sustainability such as those from the World Bank, the European Union, and UN [3]. Perhaps one the best known definitions of sustainable development is from Our Common Future and deals with how we use resources today in a way that does not compromise the ability of future generations to meet their needs [4]. Wider exposure was given to sustainable development in the 1992 UN Earth Summit in Rio de Janeiro. Besides conflicting definitions, there are opposing views to sustainability, for example how can we determine the most important needs that future generations will have [5].

Nevertheless, a sustainable future is a vision desired by all sectors in society. One must consider the social, economic and environmental dimensions of any issue in a sustainable future as shown in Figure 1. There is also an ethical dimension to sustainability, and any sustainable strategy must occur within the limits imposed by Nature. Any of the proposed schemes for attaining a sustainable future will require sustainable energy methods and practices. The transition from the 
current energy regime to an extensive use of renewable resources is not an easy task. Such transition requires, among other things, education programs that train a new and retrain the present workforce in the new energy model of sustainability: the integration of the technical issues with the economic, social and environmental implications of energy.

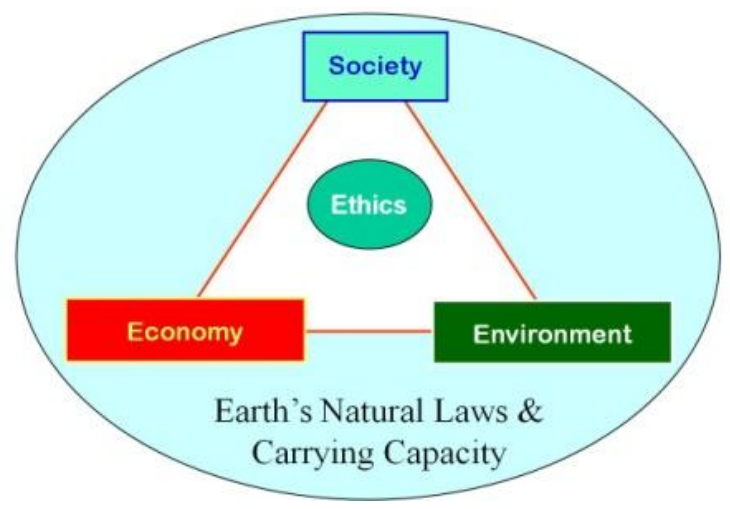

FIGURE 1: Sustainability and Ethics

This paper presents a contribution to the new and present energy workforce development challenges focusing on education activities in a Sustainable Energy Laboratory. These efforts could also be modified and applied at other places. This work is supported by grants from the Alfred P. Sloan Foundation, Air Force Research Laboratory, Department of Homeland Security and more important the Department of Education. The latter sponsors CIVIS, a Center for Resources in General Education established at the University of Puerto Rico Mayagüez (UPRM) campus to provide a new perspective in general and STEM education [6]. CIVIS, which means "citizen" in Latin, brings together faculty from Business Administration, Arts and Sciences, Agriculture and Engineering in order to develop interdisciplinary activities that further the university's mission of shaping productive and committed citizens. CIVIS challenges the traditional classification of "technical skills" and "soft-skills", substituting it by an education emphasis on the development of the professional and global skills today's marketplace requires. The Sustainable Energy Laboratory and related activities are a key component within the CIVIS Sustainable Energy Initiative [7].

\section{Sustainable Energy Initiative}

Access to reliable energy sources is one of the major challenges humanity faces in the $21^{\text {st }}$ century. The energy challenge is particularly difficult in places that lack the conventional energy sources used worldwide. However, many of such places have abundant renewable energy sources that could be tapped to meet most of the country's energy needs. Ramon Pichs, co-Chair of the UN IPCC Working Group III stated in May 2011 that "close to 80 percent of the world's energy supply could be met by renewables by mid-century if backed by the right enabling public policies. ...it is not the availability of the resource, but the public policies that will either expand or constrain renewable energy development over coming decades." The transition from the current energy regime to an extensive use of our renewable resources is not an easy one. Such transition requires better policies which in turn require education programs that train a new workforce in the new energy model of sustainability: the integration of the technical issues with the economic, social and environmental implications of energy. 
The Sustainable Energy Initiative (SEI) of the CIVIS project strives to contribute to the new energy workforce development efforts at UPRM. The SEI started in 2008 to provide students a sustainable learning context in which they could learn about sustainable energy, get motivated with the work in the area and a obtain a global perspective of their education in engineering. Within this context students are also expected to deepen their general education skills, since they need a holistic perspective to better grasp sustainable energy concepts. The SEI illustrates some of the educational opportunities not only in energy economics, but also in the integration of social issues in the analysis of a sustainable future. The SEI initiative has three main areas:

1. A module-based framework in which students can benefit from a more integrated energy perspective.

2. Experimental and real-life settings for students to understand the impact of energy in society, and outreach to K-12 and general public.

3. K-12 Outreach: Effective and numerous K-12 outreach activities mostly led by Chemical Engineering Sustainable Energy Laboratory.

\section{SEI modules}

The energy-related Student Learning Modules (SLM) cover topics directly related to a sustainable energy future such as the global impact of energy; sustainable energy technologies, energy policy, energy efficiency and conservation, health and safety issues, energy, environment and society. Because SLMs could be integrated into very diverse courses and for a diverse audience, they need to be stand-alone. Each module must start with the fundamentals, be generic and provide an overview of the topic, so that other professors can adapt and use them without the need for deep prior knowledge on the topic. Each Engineering program can expand the modules to specifically address the specific needs of their students. Professors can integrate the modules as they feel best complement their courses, depending upon the nature of the topic under discussion and the intended audience of the module. The modules are not intended for substituting any course, but to provide students with an awareness of various issues, as well as an introduction to the courses available in each of the module topics. The SLM standard length is 3 hours, although the time can be adjusted. Instructional energy modules were created for use mainly in the College of Engineering, although other colleges will also be able to use them.

\section{SEI Laboratories}

The SEI includes activities and support for the sustainable energy laboratories at UPRM. These laboratories already existed, but their scope has been greatly expanded through this project since the existing labs were mainly focused on engineering-related courses or research. CIVIS has provided the necessary tools and equipment to engage in truly interdisciplinary education and research in sustainable energy that provides a context for students to deepen their professional and general education skills. There are two laboratories supported by the SEI, in chemical engineering (Chem E) and another in electrical engineering (ECE). Equipment purchased in both labs improves their sustainable energy capabilities, and also provide hands-on experiences for modules and seminars. For example there is intensive use of equipment in the energy module "How to make Biodiesel". By the end of the funded project (2013) the ECE Sustainable Energy Lab will go from serving 200 students to 500 students per year through 
laboratories, seminars, short courses and demonstrations. By the end of the funded project (2013) the Chemical Engineering Sustainable Energy Lab will increase its outreach from about 50 students to around 400 students through laboratories, seminars, short courses and demonstrations.

\section{Support of the University mission}

The SEI directly helps UPRM's mission of preparing students to contribute towards a sustainable society and also in the never-ending mission of preparing rounded professionals, with a holistic perspective of their careers and their professional responsibility to society. In particular the SEI is aligned to the following institutional goal "To provide excellent service that will contribute to the sustainable and balanced development of our society."

The SEI modules as a group address all 9 university's student learning outcomes, thus providing a context to deepen general education skills (as seen on Table 1). By end of the funded project, the energy modules will be used in at least one energy and environment course in each Engineering Department. Furthermore, the SEI modules can be adapted to other disciplines creating the interdisciplinary link sought by CIVIS.

Table 1: Alignment of SEI Activities with UPRM's General Education Philosophy

\begin{tabular}{|l|c|c|}
\hline \multicolumn{2}{|l|}{ SEI Activity } \\
\hline Student Learning Outcome & $\begin{array}{c}\text { Learning } \\
\text { Modules }\end{array}$ & $\begin{array}{c}\text { Energy } \\
\text { Labs }\end{array}$ \\
\hline Communicate effectively & $\mathrm{X}$ & $\mathrm{X}$ \\
\hline $\begin{array}{l}\text { Identify and solve problems, think critically, and synthesize } \\
\text { knowledge appropriate to their discipline }\end{array}$ & $\mathrm{X}$ & $\mathrm{X}$ \\
\hline $\begin{array}{l}\text { Apply mathematical reasoning skills, scientific inquiry methods, } \\
\text { and tools of information technology }\end{array}$ & $\mathrm{X}$ & $\mathrm{X}$ \\
\hline Apply ethical standards & $\mathrm{X}$ & $\mathrm{X}$ \\
\hline Recognize heritage and interpret contemporary issues. & $\mathrm{X}$ & $\mathrm{X}$ \\
\hline Appraise the essential values of a democratic society. & $\mathrm{X}$ & \\
\hline $\begin{array}{l}\text { Operate in a global context, relate to a societal context, and } \\
\text { demonstrate respect for other cultures }\end{array}$ & $\mathrm{X}$ & $\mathrm{X}$ \\
\hline Develop an appreciation for the arts and humanities & & \\
\hline Recognize the need to engage in life-long learning & & \\
\hline
\end{tabular}


The number of participants of SEI activities during the 2010-2011 academic year is another way this initiative supports the university's mission:

- $\mathrm{K}-16$ students participating in all SEI activities $=600$

- Three Graduate Students (Graduate Assistants) $=3$

- Number of undergraduate students (Project Assistants) $=10$

- 5 Professors/5 Researchers leading SEI activities

The SEI also has a K-12 and general public outreach component which is the focus of the rest of this paper. This kind of outreach is essential in establishing and strengthening the pipeline to careers related to sustainability. Such SEI outreach has been led by the Chem E Sustainable Energy Lab personnel, and follows diverse stakeholder engagement strategies to cater to the diversity of the audiences reached.

\section{Stakeholder Engagement}

Chapter 23, Section III of Agenda 21 from the 1992 Rio Earth Summit states: "One of the fundamental prerequisites for the achievement of sustainable development is broad public participation in decision-making. Furthermore, in the more specific context of environment and development, the need for new forms of participation has emerged. This includes the need of individuals, groups and organizations to participate in environmental impact assessment procedures and to know about and participate in decisions, particularly those which potentially affect the communities in which they live and work. Individuals, groups and organizations should have access to information relevant to environment and development held by national authorities. This includes information on products and activities that have or are likely to have a significant impact on the environment, and information on environmental protection measures."

Given the importance of public participation/stakeholder involvement for the success of sustainable energy policy, it becomes necessary to recognize the importance of designing proper decision making structures to obtain optimal energy policy outcomes [8].

In spite of obstacles, it is unacceptable that renewable energy sources are not being used to the maximum extent possible in the U.S. Participatory structures must be created that enables local and national dialogues to reach the decisions needed to move forward with sustainable policies, beyond partisan politics. All alternatives need to include social and environmental issues as equally important as the economic issues. The present consumption patterns are simply unsustainable; the Earth does have enough resources to sustain those patters for all human beings. The burden is too high, not only to the present generation, but to coming generations. It is time to quantify the benefit to future generations of sustainable practices, understanding that this strategy could imply sacrifices today. However, we already are passing future generations a huge economic debt, why not passing them a positive legacy with sustainability [9].

In order to move to a sustainable future, all energy stakeholders need to participate in the generation, evaluation and implementation of long-term strategies: Every sector must assume its responsibilities in enabling a sustainable energy future. Collaborations among government, industry, commercial sector and citizens need to be established to shift the current adversarial 
positions to collaborative relationships, from mutual distrust to a serious and lasting commitment for the public good, Also, the establishment of policies that integrate the social, environmental and economic dimensions of energy are required. National Dialogues that are inclusive and constructive are also needed. That process should yield actions that are measurable and decisive so that we can hope to achieve a more sustainable future. Besides economical considerations, we need to integrate social and environmental justice. To re-think energy systems and energy consumption we must go beyond the utilitarian view of cost-benefit analysis [9].

Energy stakeholders must have trustworthy mechanisms to constructively discuss concerns and viewpoints in dealing with the challenges of an increased use of renewable energy resources. For example, forums to allow groups to reach common ground from which to devise concrete actions for increased use of renewable energy resources. The forum would have to deal with the uncertainty issues and regional variations mentioned earlier. The forum would also have to manage trust problems that might exist among groups that have traditionally had contentious relationships.

Any stakeholder engagement mechanism requires some form of common, transparent way of providing timely information to all sectors before policy decisions are final. This is especially true considering that many energy decisions are usually made based on hierarchal, top-down approaches. We argue that one of the causes for polarization in public debate is the longstanding, limited and usually late participation of the public in the policy making process. It is time to level the playing field by changing that paradigm in a way so that no singular group or sector is favored, but all parties benefit. A transparent communications system can be used as a tool for all stakeholders to voice their concerns or suggestions regarding energy. Transparency should not be feared but rather embraced for its accountability.

Effective stakeholder engagement is a vital component in the development of sustainability practices and in promoting sustainable energy careers and interest. The main objective of the energy stakeholder engagement framework presented in Table 2 is to increase awareness resulting in a more responsible citizen willing to contribute to the solution of the energy problems. The target audience includes individuals, energy producers, businesses, governments, non-governmental organizations, and communities [8].

The next sections present some of the stakeholder engagement activities led by the Chem E Lab to further sustainable energy dialogues and actions. These strategies strive to follow a constructivist approach, emphasizing the integration of the perspectives from different societal groups [10]. A constructivist approach seeks to bring different values, definitions, attitudes, and knowledge to sustainability. These approaches can positively affect processes and outcomes [11] particularly when dealing with complex problems such as sustainability [12-13]. 
Table 2: Examples of Stakeholder Engagement Activities

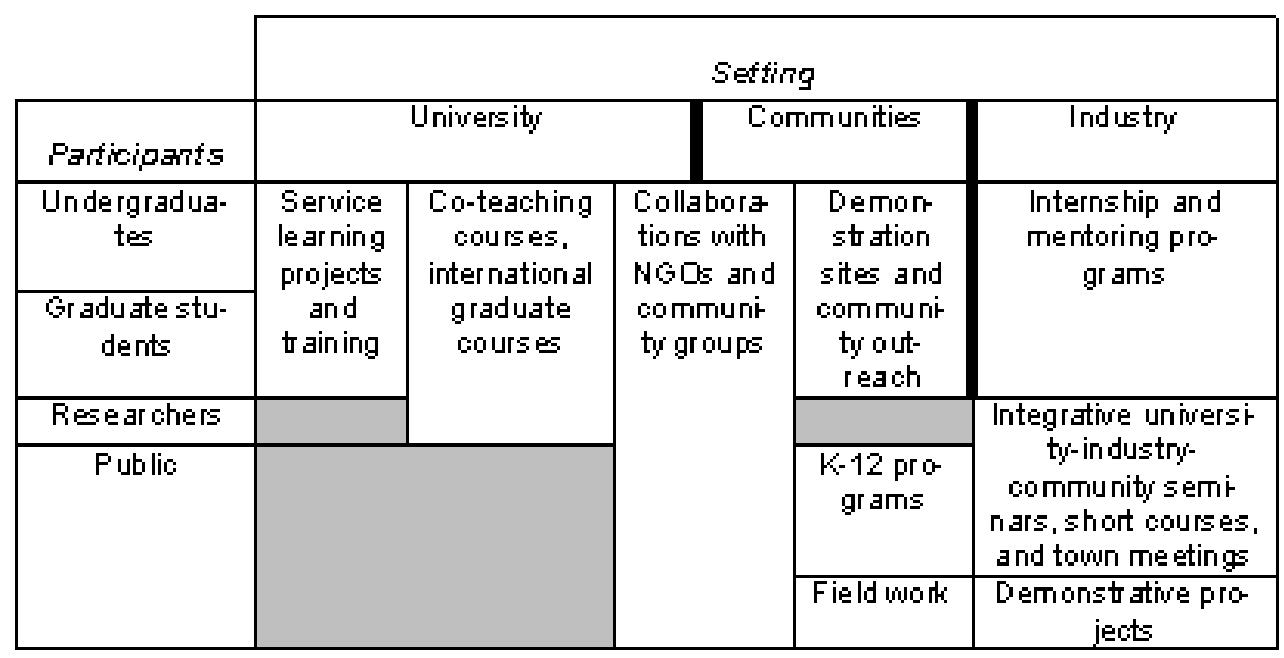

\section{Chem E Sustainable Energy Lab}

The Sustainable Energy Laboratory adopted the definition of Sustainability as "a path forward that allows humanity to meet current environmental and human health, economic, and societal needs...". The lab focus is Sustainable Energy that merges economically viable Renewable Energy technologies with Social Equity and Ethics implications. The economic component also includes externalities or hidden costs. The Vision, A Sustainable Energy Driven Society.

In general the Learning Objective is to educate and convert to Sustainable Energy utilizing several hands on and/or visual modalities. The Target Audience are students and the public in general. Each audience requires strategic methodologies. These two audiences and their respective activities will be discussed separately.

\section{Retraining and General Public}

The general public has different challenges related more to logistics. It should be mentioned that the Chem E Sustainable Energy Lab team leader is recognized in Puerto Rico as an expert in Sustainable Energy. At least once a month presentations are delivered to professional organizations (50 to 100 attending, engineers and chemists) for continuous education credit in the area of Sustainable Energy. An outreach collaboration with a major city benefitted from their self governance philosophy that allows the organization of Town Hall meetings with relatively ease. Eleven energy town hall meetings were organized between 2009/10 to kickoff a series of demonstrations projects planned for that municipality. These energy projects ( $\sim 1.5$ million investment) were co-sponsored by ARRA funds. The projects were based on a study on the feasibility of sustainable energy studies also led by the team leader of the Chem E Lab. 


\section{A New Energy Workforce}

The SEI has had very effective and numerous outreach activities mostly led by the Chem E Lab personnel. A condensed version of the sustainable energy modules has been delivered to high school students and the general public as part of the outreach efforts of the SEI. Demonstrations using the sustainable energy labs are included on many seminars. Some examples of K-12 outreach include the sustainable energy module delivered on September $16^{\text {th }}$ at the SEI Chemical Engineering Laboratory. The average assessment results for this seminar were 4.8 out of 5 .

The Sustainable Energy (SE) module was also taught in numerous occasions because this module is the introductory module on sustainability, and is thus requested through invitations from various groups. This module also allows for adaptation depending on the audience. For example, there are three versions of the SE module: Renewable energy sources (mostly based on a renewable energy sources, technologies and resource assessment), Biodiesel and Energy Externalities. This module is also easier to couple with one of the General Education modules. The module has been taught in chemical engineering, electrical engineering and mechanical engineering courses. The module was also taught to a Geology students association. This is an important seminar because it took the SEI modules out of engineering, and also it was delivered by a non-SEI faculty. The Chem E group created a module on Biodiesel as a spin-off of the SE module. This module has been uploaded to the Connexions ${ }^{\circledR}$ website (www.cnx.org) and linked to the CIVIS project.

Attention span is a challenge for K-20 especially K-12s. Highly enthusiastic undergraduate and graduate students are critical for K-12 workshops since they act both as presenters and mentors. These workshops must be attractive and interesting to the audiences. Presently, two workshops are organized per semester for this audience with 20-30 students per workshop. Undergraduate students are also a challenge. A combination of lecture plus demonstration has been very effective based on the evaluations (4.80/5.0). Similar to K-12, two workshops are organized per semester with 20-30 students per workshop. There are also approximately 5-10 undergraduate students as part of the sustainable energy laboratory staff. They are involved in research activities related to Sustainable Energy. Some examples of the activities performed at the lab for middle and high school students include the use of the Microscope Station in the analysis of microalgae cells and a demonstration of the process for oil extraction from Microalgae using Ultrasound Methodology.

The last component of undergraduate education led by Chem E Lab personnel is the modification of CHEM E Design $1 \& 2$ courses towards a sustainability philosophy. Both are taught exclusively by the laboratory lead professor to 90 students per year per course. Regarding graduate students, over 10 students worked with the team leader in renewable energy related projects. In addition, the team leader developed a Biorefinery course requested by UNAPEC, a university at the Dominican Republic.

\section{Going Beyond Typical K-12 Outreach}

On many outreach seminars, there are demonstrations of energy efficient devices and scaled versions of renewable systems. On one occasion a group of $10 \mathrm{high}$ school students participated with the project researchers in an "energy walk-through" of their school. This is an activity in which an inventory of electric equipment and its use is done for a location. The walk-through lasted approximately 3 hours, and it was both a mentoring and a learning opportunity for the 
students. Students were active participants in this activity, which resulted in a report to school on how to save energy through better conservation and efficiency practices. The same school also invited Chem E Lab personnel for further seminars to their personnel, and asked for help in implementing their sustainable policies for the school. As a result, the School was able to get a grant for the installation of a Photovoltaic system in their premises. This $60 \mathrm{~kW}$ photovoltaic system is the largest system installed in a school in Puerto Rico. The Chem E Lab Personnel were key in this achievement, and have linked that collaboration with field trips by undergraduate students to observe first-hand the $60 \mathrm{~kW}$ photovoltaic system operation. This also provides a practical link to the SE module. The average evaluation of this activity was 4.8 out of 5. This type of outreach is beyond the traditional way, and shows a long term commitment to a true transition to a sustainable energy future.

Some of the presentations for high school students were in collaboration with a University Center for access to disadvantaged youth and at the City of Caguas. These outreach collaborations seek to improve the chances of low-income students to attend college. The SEI collaboration exposes them to sustainable energy concepts, to encourage them to follow careers in science and engineering. For these particular collaborations, the module started with a 30minute presentation on energy concepts, followed by group work in which students build a model of a car that is powered by the sun. The students then held a competition to determine which of their solar cars was the fastest. This type of activity promotes awareness among students for energy technologies and issues, including energy efficiency and renewable energy. Assessment results for outreach activities have been overwhelmingly positive, with evaluations over $80 \%$ in most regards. The Chem E team led this outreach effort.

\section{Assessment}

Assessment results for the SEI Modules are briefly discussed. The assessment includes questions to qualify the impact of the energy modules on student understanding of energy issues. All answers evidenced that students gained new knowledge and expanded their insight about energy issues. Typical evaluation scores were greater than 4.8/5.0. Furthermore, some students commented that the module "broadened the social aspect of the profession" and also "Now I realize that I should not take into account the engineering aspects alone". These comments show that the modules were effective in making students think beyond their specific discipline, and make connections to the general education skills they learned in previous courses. The assessment also included questions to students about the links of the module to nine student learning outcomes (SLO), which summarizes the general education philosophy (what all students should be able need to do by the time they graduate). These were presented before in Table 1 .

Students are asked to related what they learned in the module with their classes. For example, in a Chemical Engineering capstone the sustainable energy module was delivered with focus on energy externalities. Students were asked to apply in their designs the analysis of externalities. Students were able to successfully apply the concepts learned in the module, correctly summarizing the key topics from the seminar as evidenced in their reports:

- "(we need to)...evaluate the environmental burdens associated with a product by identifying and quantifying energy and material usage, and environmental releases"

- "... the cost of operating the plant does not rely only on operation and the workers, but also on everything around us." 
- “...a paradigm shift towards sustainability.”

The students were able to apply concepts related to externalities in their designs and present alternatives to deal with those:

- "Possible externalities to our innovative product include health problems to consumers due to exposure to our silver nanoparticles and silicate compounds."

- "...we analyzed thoroughly the consequences of (design) decisions in the environment and in the people's health."

- "... the silver nanoparticles can become an environmental issue since our nanoparticles are not biodegradable. Also, if we don't find out a better way of recycling our product we can end up with external costs to our aquatic life, the soils and consequently our own health's because this is all a cycle."

- "...one positive externality regarding our product is that it can minimize the need of landfills since it is more durable and resistant..."

- “...Some of these externalities are (related to) the disposal of the textiles. The company has a recycle program that, if the buyers don't follow the instructions, the nanoparticles of $\mathrm{TiO}_{2}$ can be dispersed inadequately in the environment. For this reason, we are committed to educate the buyers."

Other outreach activities include seminars and workshops to the general public and professional organizations in Puerto Rico on sustainable energy and energy public policy. For example, seminars and workshops to Math and Science teachers (some of them 3 hours long) merging some of the sustainable modules were organized by the SEI. There are also periodic presentations to professional organizations such as the PR Professional Engineers State Society and other public and private universities in the state. During the fourth year the SEI labs will host 3 Middle school students to support their Science Fair projects. Graduate students and Senior Researchers will act as Mentors to these students. Assessment results for public outreach activities have been overwhelmingly positive, with evaluations over $80 \%$ in most instances as can be observed in Figure 2.

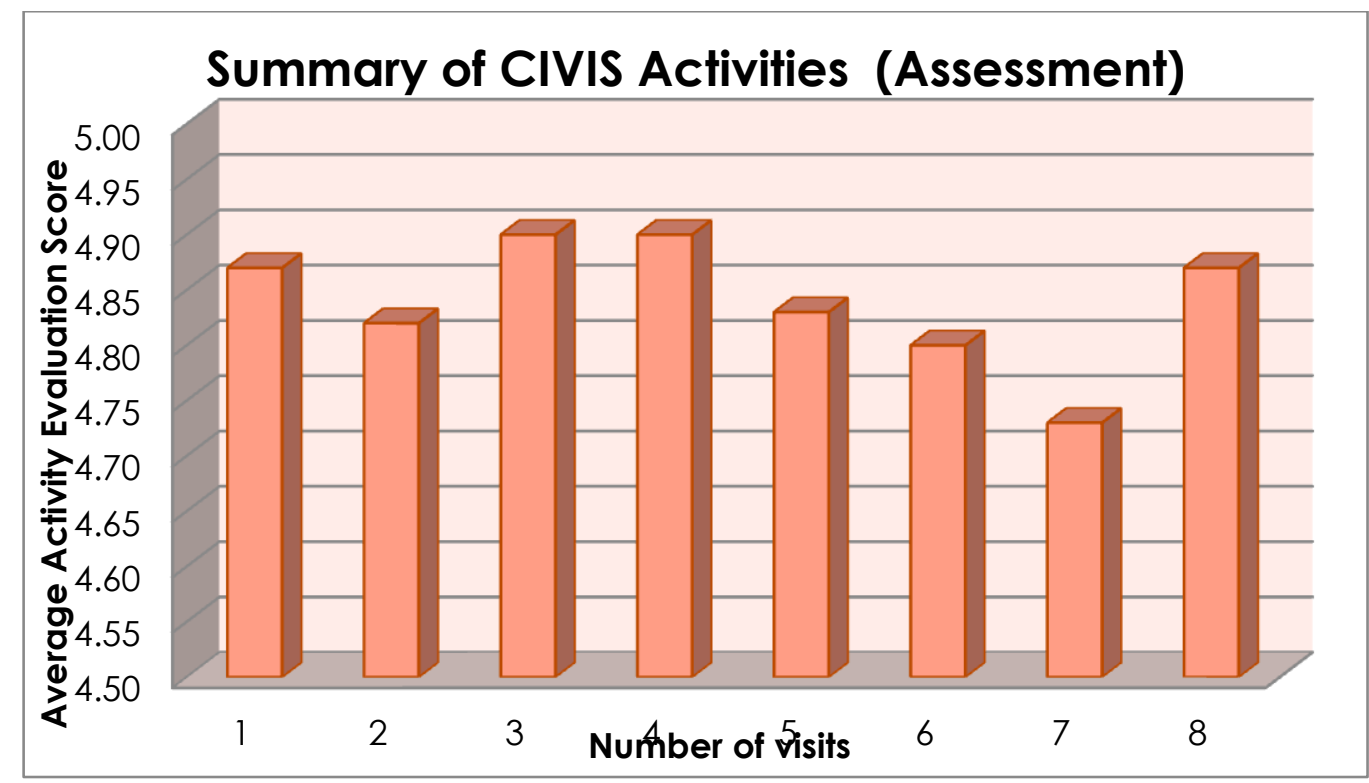

Figure 2: Summary of Assessment Results for Chem E Lab outreach activities 


\section{Institutionalization, Dissemination and Impact Beyond the Project}

Our main strategy to achieve institutionalization of the SEI is to show faculty the benefits of the modules and the laboratories. The SEI is a cornerstone of many other proposals to various agencies. The Chem E Team has led many of those efforts..

SEI material was used to develop a Renewable Energy Option within the Bachelors degree at the University APEC (Dominican Republic). The SEI is also collaborating with other on-going projects led by the Chem E Lab team. Conversations are on-going for the Green Campus Initiative to use and adapt the SEI modules into their activities. This collaboration will be more productive once SEI modules are uploaded to Connexions ${ }^{\circledR}$ The dissemination and constant use of SEI material within the host university will increase sustainability knowledge among engineering faculty and students, creating the conditions to ease institutionalization of the SEI activities and expanding the impact of the outreach activities and the pipeline to sustainability careers led by the Chem E Lab.

\section{Concluding Remarks}

The Sustainable Energy Laboratory in the Chemical Engineering Department has been instrumental in the effective incorporation of sustainability into chemical education targeting audiences (hundreds per year) from the whole spectrum: K-12, undergraduate students, graduate students and the general public. The latter includes strong alliances with various critical stakeholders from the energy sector. The laboratory's cultural transformation started in 1995 focusing mainly on "traditional" renewable energy. Today the focus increased to include sustainability principles such as social equity, ethics and community participation but again with energy as the central theme. In summary these unique education program pipeline trains a new and retrain the present workforce in the new energy model of sustainability: the integration of the technical issues with the economic, social and environmental implications of energy.

\section{Acknowledgements}

The work described in this paper was primarily supported by the U.S. Department of Education under grant $84.031 \mathrm{~S}$. The excellent work of undergraduate research assistants at the Chemical Engineering Lab is also acknowledged.

\section{Bibliography}

[1] Moffat, J.; Hanlery, R.; Wilson, M. Measuring and Modelling Sustainable Development, Parthenon, New York, 2001.

[2] Norton, B. Sustainability, University of Chicago Press, 2005.

[3] Hake, J.; Eich,R. "Energy and Sustainable Development," in Energy and Culture, Ashgate, UK, 2006.

[4] United Nations. 1987. Our Common Future, The World Commission Report on Environment and Development, Oxford Press.

[5] Beckerman, W. A Poverty of Reason, Independent Institute, Oakland, 2003.

[6] O'Neill-Carrillo, E. Collins, D. López Garriga, J. Macchiavelli, R. Cruz, J. A. “Center for Resources in General Education (CIVIS): Towards Student Success in General and STEM Education," Proceedings of the $39^{\text {th }}$ ASEE/IEEE Frontiers in Education Conference, October 18 - 21, 2009, San Antonio, TX.

[7] O'Neill-Carrillo, E., Colucci-Rios, J., Irizarry-Rivera, A. "Integrating Sustainable Energy in Engineering Education" Proceedings of the IASTED International Conference on Power and Energy Systems, November 69, 2011, Pittsburgh, PA. 
[8] O’Neill-Carrillo, E. Frey, W. Ortiz-García, C. Irizarry-Rivera, A. Pérez-Lugo, M. Colucci-Rios, J. “Advancing a Sustainable Energy Ethics Through Stakeholder Engagement," Proceedings of Energy 2030: IEEE Conference on Global Sustainable Energy Infrastructure, November 2008, Atlanta, GA.

[9] O’Neill-Carrillo, E. Pérez-Lugo, M. Ortiz-García, C. Irizarry-Rivera, A. Colucci-Ríos, J. "Sustainable Energy: Balancing the Economic, Environmental and Social Dimensions of Energy," Proceedings of Energy 2030: IEEE Conference on Global Sustainable Energy Infrastructure, November 2008, Atlanta, GA.

[10] Hannigan. Environmental Sociology, 2nd Edition. London: Routledge, 2006.

[11]R. Bañares-Alcántara. "Perspectives on the potential roles of engineers in the formulation, implementation and enforcement of policies," Computers \& Chemical Engineering, Vol. 34, No. 3, March 2010, Pages 267-276.

[12] Colucci, J.A.; O’Neill-Carrillo, E.O.;Irizarry-Rivera, A. "Renewable Energy in the Caribbean, A Case Study from Puerto Rico" Chapter in Environmental Management, Sustainable Dev. and Human Health, ISBN 978-0415-46963-0, CRC Press, 2008.

[13] O’Neill-Carrillo, E. Ortiz-García, C., Pérez, M. Baigés, I. Minos, S. "Experiences with Stakeholder Engagement in Transitioning to an Increased Use of Renewable Energy Systems," Proceedings of the IEEE International Symposium on Sustainable Systems and Technology, Washington, DC, May 2010. 